\title{
Synthesis of trifluoromethyl ketones by nucleophilic trifluoromethylation of esters under a fluoroform/KHMDS/triglyme system
}

\author{
Yamato Fujihira ${ }^{1}$, Yumeng Liang ${ }^{2}$, Makoto Ono ${ }^{1}$, Kazuki Hirano ${ }^{2}$, Takumi Kagawa ${ }^{3}$ \\ and Norio Shibata ${ }^{*} 1,2,4$
}

\section{Letter}

Address:

${ }^{1}$ Department of Life Science and Applied Chemistry, Nagoya Institute of Technology, Gokiso, Showa-ku, Nagoya 466-5888, Japan,

${ }^{2}$ Department of Nanopharmaceutical Sciences, Nagoya Institute of Technology, Gokiso, Showa-ku, Nagoya 466-5888, Japan, ${ }^{3}$ Tosoh Finechem Corporation, 4988, Kaiseicho, Shunan, 746-0006, Japan and ${ }^{4}$ Institute of Advanced Fluorine-Containing Materials, Zhejiang Normal University, 688 Yingbin Avenue, 321004 Jinhua, China

Email:

Norio Shibata* - nozshiba@nitech.ac.jp

* Corresponding author

Keywords:

fluoroform; greenhouse gas; HFC-23; trifluoromethyl ketones;

trifluoromethylation
Beilstein J. Org. Chem. 2021, 17, 431-438.

https://doi.org/10.3762/bjoc.17.39

Received: 03 November 2020

Accepted: 02 February 2021

Published: 12 February 2021

This article is part of the thematic issue "Organo-fluorine chemistry V".

Guest Editor: D. O'Hagan

(c) 2021 Fujihira et al.; licensee Beilstein-Institut.

License and terms: see end of document.

\begin{abstract}
A straightforward method that enables the formation of biologically attractive trifluoromethyl ketones from readily available methyl esters using the potent greenhouse gas fluoroform $\left(\mathrm{HCF}_{3}, \mathrm{HFC}-23\right)$ was developed. The combination of fluoroform and $\mathrm{KHMDS}$ in triglyme at $-40{ }^{\circ} \mathrm{C}$ was effective for this transformation, with good yields as high as $92 \%$. Substrate scope of the trifluoromethylation procedure was explored for aromatic, aliphatic, and conjugated methyl esters. This study presents a straightforward trifluoromethylation process of various methyl esters that convert well to the corresponding trifluoromethyl ketones. The tolerance of various pharmacophores under the reaction conditions was also explored.
\end{abstract}

\section{Introduction}

In recent decades, organofluorine molecules have received widespread attention in the field of medicinal chemistry [1-4] The introduction of fluorine(s) into organic molecules usually leads to significant changes in the chemical and physicochemical properties of the original compounds $[5,6]$. Hence, the fluorination and related fluoro-functionalization of drug candi- dates are powerful strategies in drug design to appropriately bias their biological properties, bioavailability, and ADME $[7,8]$. While tremendous methodologies have been developed for the synthesis of organofluorine compounds [9,10], many of the laboratory methods are not always suitable for industrial production in terms of their synthetic complexity, handling, and 
cost of target compounds [11-15]. Thus, the development of low-cost and straightforward chemical synthetic technologies, including fluorination and trifluoromethylation, are matters of considerable importance to pharmaceutical and agrochemical industries. Fluoroform $\left(\mathrm{HCF}_{3}, \mathrm{HFC}-23\right)$ is an industrial byproduct of polytetrafluoroethylene synthesis and has become an ideal, economical feedstock for trifluoromethyl $\left(\mathrm{CF}_{3}\right)$ compounds. Rather than decomposing $\mathrm{CF}_{3}$ compounds, it would be better to maximize the efficiency of their use [16-18]. However, taming $\mathrm{HCF}_{3}$ as a trifluoromethylation agent is a challenge in organic chemistry [19-28], although recent rapid progress in the chemistry of $\mathrm{HCF}_{3}$ by Grushin (for $\mathrm{CuCF}_{3}$ ) [29-37], Prakash (for $\mathrm{KCF}_{3}$ ) [38], and others [39-44], including our group [45$50]$, has dramatically improved the prospects. One of the problems facing the treatment of $\mathrm{HCF}_{3}$ for nucleophilic trifluoromethylation reactions is the low stability of the directly generated $\mathrm{CF}_{3}$ anion $\left(\mathrm{CF}_{3}{ }^{-}\right)$for decomposing to difluorocarbene $\left(: \mathrm{CF}_{2}\right)$ and fluoride $\left(\mathrm{F}^{-}\right)$(Scheme 1a). Due to the formation of highly stable fluoride salts (MF), the breakdown of $\mathrm{CF}_{3}{ }^{-}$into difluorocarbene in the presence of alkali $\left(\mathrm{M}^{+}\right)$and other metal cations is favored. In earlier studies, the solvent $N, N$-dimethylformamide (DMF), was essential for nucleophilic trifluoromethylation by $\mathrm{HCF}_{3}$ since DMF acts as a $\mathrm{CF}_{3}$ anion reservoir that is used as a hemiaminaloate adduct $\left[\mathrm{Me}_{2} \mathrm{NCH}(\mathrm{O}) \mathrm{CF}_{3}\right]-$ (Scheme 1b) [19-28]. Although the taming $\mathrm{CF}_{3}$ anion had been an elusive problem for decades, it has been dramatically progressed in recent years by the substantial works by Grushin [51-53] and Prakash [54]. Our group reported novel DMF-free systems for the nucleophilic trifluoromethylation reaction using $\mathrm{HCF}_{3}$, including the phosphazene base $\mathrm{P} 4-t-\mathrm{Bu}(\mathrm{P} 4-t-\mathrm{Bu})$, in 2013 (Scheme 1c) [45] and a potassium tert-butoxide ( $t$-BuOK) or potassium hexamethyldisilazide (KHMDS)/glyme combination in 2018 (Scheme 1d) [46]. The success of our DMF-free systems lies in the generation of sterically demanding cationic species, $[\mathrm{P} 4-t-\mathrm{Bu}] \mathrm{H}^{+}$or glyme capsulized $\mathrm{K}^{+}$, resulting in the stabilization of $\mathrm{CF}_{3}^{-}$from $\mathrm{HCF}_{3}$ by ion separation. The sterically demanding $[\mathrm{P} 4-t-\mathrm{Bu}] \mathrm{H}^{+}$or encapsulation of $\mathrm{K}^{+}$by glymes effectively inhibits the contact of $\mathrm{CF}_{3}{ }^{-}$to $\mathrm{K}^{+}$, preventing decomposition into $\mathrm{CF}_{2}$ and $\mathrm{KF}$. The isolated $\mathrm{CF}_{3}$ is rather naked with a highly nucleophilic character, which is suitable for nucleophilic trifluoromethylation reactions. The $\mathrm{K}^{+}$and glyme combination is particularly useful for the nucleophilic trifluoromethylation of carbonyl compounds to trifluoromethyl carbinols because it does not require any expensive reagents nor very low-temperature conditions. Although the reaction has a broad substrate scope of embracing ketones, chalcones and aldehydes, the transformation of esters to trifluoromethyl ketones by this protocol was never examined [46].

Trifluoromethyl ketones (TFMKs) are valuable fluorine-containing synthetic targets of bioactive compounds $[55,56]$ that behave as mimics of the tetrahedral transition-state intermediate of enzymatic hydrolysis of esters and amides by stabilizing their hydrates (Figure 1a) [57]. In fact, the TFMK moiety is a proven effective metal chelator in various enzyme inhibitors (Figure 1b) [58-65].

Several useful methods exist for preparing trifluoromethyl ketones $[66,67]$, such as the direct trifluoromethylation of esters by the Ruppert-Prakash reagent $\left(\mathrm{Me}_{3} \mathrm{SiCF}_{3}\right)$ [68-71], but the use of $\mathrm{HCF}_{3}$ for this transformation reaction is still limited. In 1998, Russel and Roques examined the transformation of methyl benzoate to trifluoromethyl phenyl ketone with $\mathrm{HCF}_{3}$ in the presence of KHMDS or KH/DMSO in DMF, but the method required DMF and only a single example was indicated (Scheme 2a) [23]. Prakash and co-workers showed the first example of the DMF-free preparation of trifluoromethyl phenyl ketone with $\mathrm{HCF}_{3}$ in the presence of KHMDS in THF, but they did not examined the scope of the reaction (Scheme 2b) [38]. In 2018, Szymczak and co-workers showed a single example of the preparation of phenyl trifluoromethyl ketone using $\mathrm{HCF}_{3}-$ derived borazine $\mathrm{CF}_{3}{ }^{-}$in $29 \%$ yield (Scheme 2c) [43]. Very recently, Han, Lian, and co-workers reported that a protocol using diisopropylaminosodium ( $\mathrm{NaDA}$ ) was useful for the tri- a)

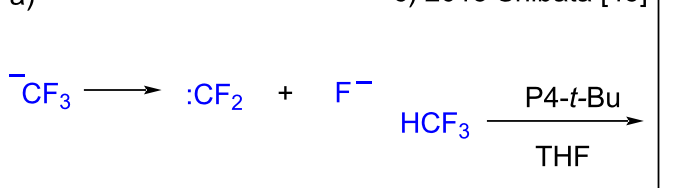

b)

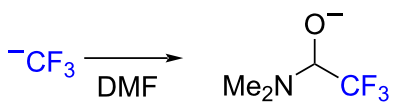

c) 2013 Shibata [45] -

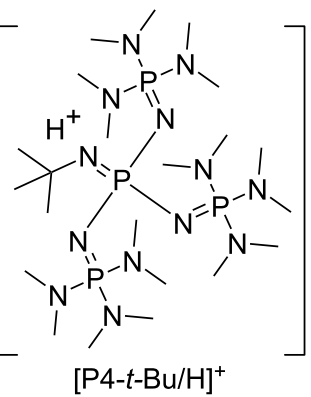

d) 2018 Shibata [46]

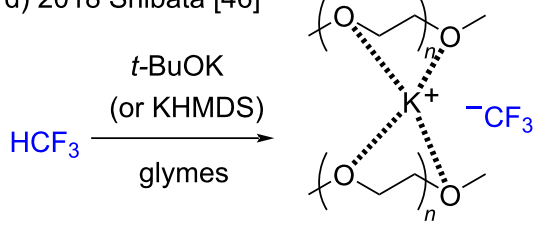

triglyme: $n=3$ tetraglyme: $n=4$

Scheme 1: Chemistry of the $\mathrm{CF}_{3}$ anion generated from $\mathrm{HCF}_{3}$. a) Decomposition of the trifluoromethyl anion to difluorocarbene and fluoride. b) $A$ hemiaminaloate adduct of $\mathrm{CF}_{3}$ anion to DMF. c) Formation of the $\left[\mathrm{P} 4-t-\mathrm{Bu}^{\mathrm{N}} \mathrm{H}^{+} \mathrm{CF}_{3}\right.$ anion salt. d) Encapsulation of $\mathrm{K}^{+}$by glymes. Transformation of esters to trifluoromethyl ketones. 
a)

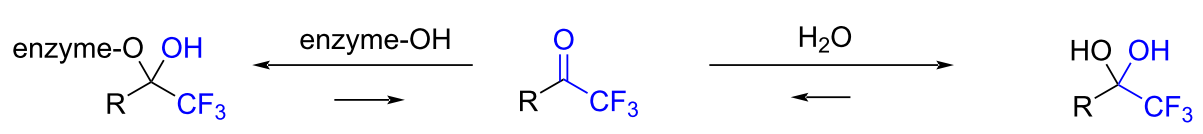

transition-state mimic

b)

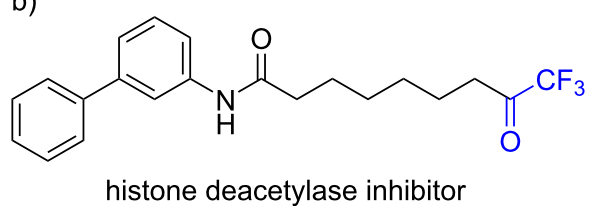<smiles>CCCCCCCCCCCCCCCC(=O)C(F)(F)F</smiles>

fatty acid amide hydrolase inhibitor<smiles>CCCCC/C=C/C/C=C/C/C=C/C/C=C/CCCC(=O)C(F)(F)F</smiles>

phospholipase A2 inhibitor<smiles>O=C(Cc1nc2ccccc2o1)C(F)(F)F</smiles>

anti-Gelicobacter pylori activity<smiles>COc1ccc(-c2cc(C(=O)C(F)(F)F)c(C)n2-c2ccc(F)cc2)cc1</smiles>

Me-D-PhePro、<smiles></smiles>

thrombin inhibitor<smiles>CC(C)(C)OC(=O)N[C@@H](Cc1ccccc1)C(=O)CNCC(=O)NC(CC1CCCCC1)C(=O)C(F)(F)F</smiles>

Figure 1: Trifluoromethyl ketones. a) Hydrolysis of trifluoromethyl ketones. b) Selected examples of biologically active trifluoromethyl ketones.

fluoromethylation of esters to trifluoromethyl ketones with $\mathrm{HCF}_{3}$ at $-60{ }^{\circ} \mathrm{C}$ (Scheme 2d) [44]. However, the preparation of $\mathrm{NaDA}$ was rather complicated and required pre-mixing of diisopropylamine, tetramethylethylenediamine (TMEDA), isoprene, and even more tedious "dispersion sodium" in $n$-heptane at 25 ${ }^{\circ} \mathrm{C}$ for $4 \mathrm{~h}$, before the reaction of esters with $\mathrm{HCF}_{3}$ at $-60{ }^{\circ} \mathrm{C}$. We herein extend our glyme strategy [50] shown in Scheme 1d,

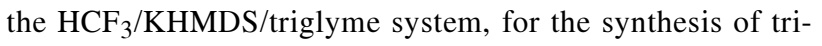
fluoromethyl ketones from esters (Scheme 2e). The combination of $\mathrm{HCF}_{3}$ and $\mathrm{KHMDS}$ in triglyme at $-40{ }^{\circ} \mathrm{C}$ was found to be effective for this transformation, with good yields as high as $92 \%$. The substrate scope of the trifluoromethylation procedure was explored for aromatic, aliphatic, and conjugated methyl esters. This study presents a straightforward trifluoromethylation process of various methyl esters that convert well to the corresponding trifluoromethyl ketones. The tolerance of various pharmacophores under the reaction conditions was also explored.

\section{Results and Discussion}

We first examined the trifluoromethylation reaction of methyl 2-naphthoate (1a) as a model substrate for $\mathrm{HCF}_{3}$ to optimize the reaction conditions (Table 1). Following our glymes strategy, we initially used $t$ - $\mathrm{BuOK}$ as the base in triglyme, and the desired trifluoromethyl ketone 2a was obtained in $29 \%$ yield (Table 1, entry 1). We next carried out the reaction in other solvents, THF (2a, 5\%, Table 1, entry 2 ) and toluene (2a, $0 \%$, Table 1, entry 3 ), and confirmed the advantage of the triglyme that was used (Table 1, entries 1-3). Increasing the amount of $t$-BuOK to 4.0 equiv did not improve the yield (25\%) of $\mathbf{2 a}$ (Table 1, entry 4). When we used KHMDS to replace $t$-BuOK, the yield of 2a improved significantly to $57 \%$ (Table 1, entry 5). As expected, tetraglyme, instead of triglyme, gave a similar good yield of $59 \%$ (Table 1, entry 6 ), while the transformation decreased significantly when diglyme was used (2a, 29\%, Table 1, entry 7). Interestingly, when we stopped the reaction after $4 \mathrm{~h}$, the yield increased to $76 \%$ (Table 1, entry 8 ). On this basis, we attempted to reduce the amount of $\mathrm{HCF}_{3}$ to 1.1 equiv and found that the yield was not sacrificed, yielding $75 \%$ of $\mathbf{2 a}$ (Table 1, entry 9). Other optimized reaction conditions did not improve the yield (see Supporting Information File 1 for an extensive list of reaction conditions, Table S1).

We explored the substrate scope of this trifluoromethylation reaction with the optimized conditions in hand (entry 9, Table 1). Various carboxylic esters were investigated in the 
a) 1998 Russell and Roques [23]

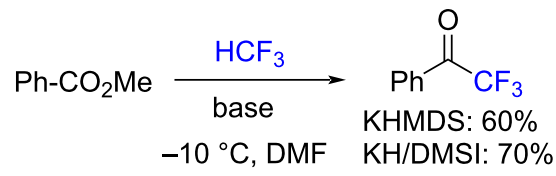

$$
\begin{aligned}
& 1 \text { example }
\end{aligned}
$$

b) 2012 Prakash [38]

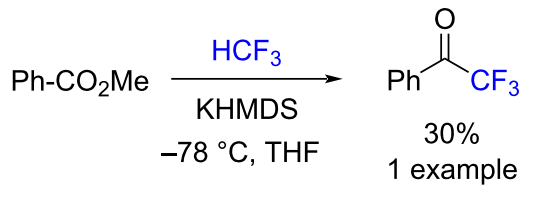

c) 2018 Szymczak [43]

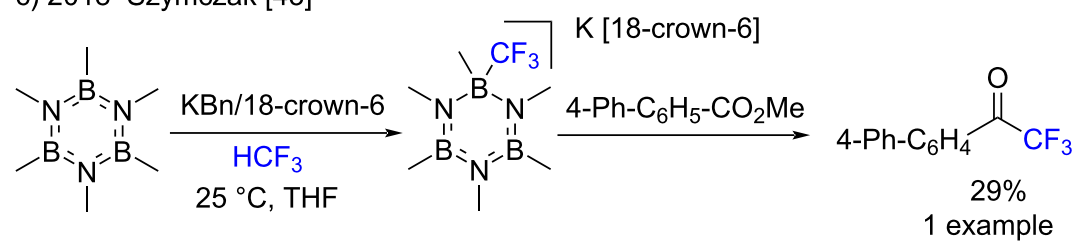

d) 2019 Han and Lian [44]

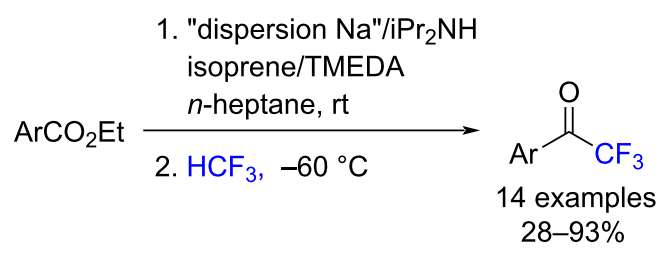

e) this work

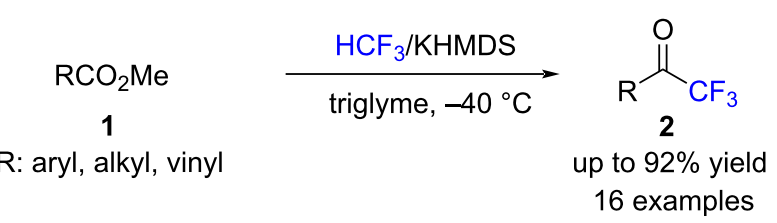

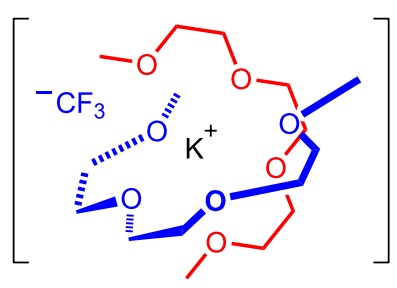

Scheme 2: Trifluoromethylation of esters by $\mathrm{HCF}_{3}$ by a) Russell and Roques (1998), b) Prakash and co-workers (2012), c) Szymczak and co-workers (2018), d) Han, Lian and co-workers (2019), and e) our group in this work.

Table 1: Optimized reaction conditions for the conversion of $\mathbf{1 a}$ to $\mathbf{2 a}$.

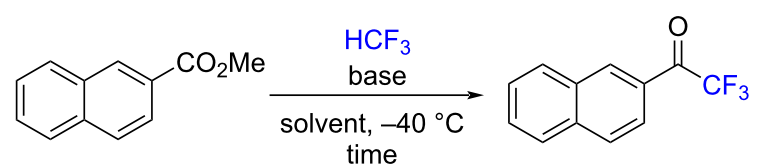

$1 \mathrm{a}$

time

$2 \mathbf{a}$

\begin{tabular}{lllll}
\hline Entry & Base (equiv) & Solvent & Time & Yield (\%) \\
\hline 1 & $t$-BuOK (2.0) & triglyme & overnight & 29 \\
2 & $t$-BuOK (2.0) & THF & overnight & 5 \\
3 & $t$-BuOK (2.0) & toluene & overnight & 0 \\
4 & $t$-BuOK (4.0) & triglyme & overnight & 25 \\
5 & KHMDS (2.0) & triglyme & overnight & 57 \\
6 & KHMDS (2.0) & tetraglyme & overnight & 59 \\
7 & KHMDS (2.0) & diglyme & overnight & 29 \\
8 & KHMDS (2.0) & triglyme & 4 h & 76 \\
$9^{\mathrm{b}}$ & KHMDS (2.0) & triglyme & $4 \mathrm{~h}$ & $75(71)^{\mathrm{c}}$ \\
\hline
\end{tabular}

aDetermined by ${ }^{19} \mathrm{~F}$ NMR using a crude mixture with trifluorotoluene as the internal standard. ${ }^{b} \mathrm{HCF}_{3}$ was 1.1 equiv. Isolated yield. presence of 1.1 equiv of $\mathrm{HCF}_{3}$ and two equiv of KHMDS (Scheme 3). Methyl 2-naphthoate (1a) gave 2a in 75\% yield, but sterically demanding methyl 1-naphthoate (1b) gave the desired trifluoromethyl ketone $\mathbf{2 b}$ in only lower yield (37\%). Functionalities on the benzene ring at the para-position were well-tolerated in the KHMDS/glyme system. Halogen groups, such as chloro (1c), bromo (1d), and reactive iodo (1e) substitutions were also tolerated, resulting in the corresponding trifluoromethyl aryl ketones in moderate yields (56-63\%) under basic conditions. The alkyl groups of tert-butyl (1f)- and cyclohexyl (1g)-substituted methyl benzoate derivatives, biphenyl benzoate (1h), and electron-donating 4-methoxybenzoate, were nicely transformed into aryl trifluoromethyl ketones in moderate to high yields (45-92\%). Aryl substrates with a halogen attached at the meta- and ortho-positions were also accepted to furnish the desired products $(\mathbf{2} \mathbf{j}-\mathbf{m})$ in good yields (66-82\%). Moreover, di-substituted benzoate (1n), sterically demanding methyl adamantly carboxylate (1o), and conjugated methyl ester (1p) transformed effectively into trifluoromethyl ketones (2o-p) in moderate yields (50-62\%). A gram-scale reaction was also 


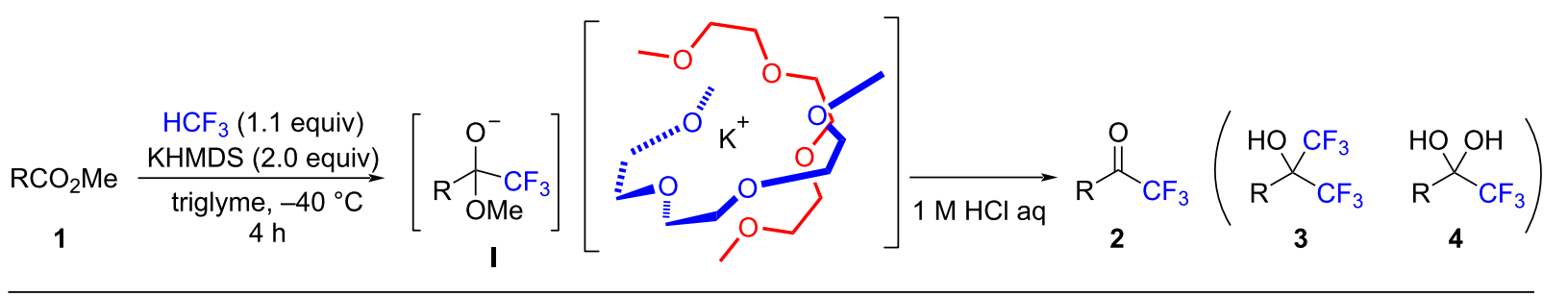<smiles>O=C(c1ccc2ccccc2c1)C(F)(F)C(F)(F)F</smiles><smiles>O=C(c1ccc(Cl)cc1)C(F)(F)F</smiles><smiles>O=C(c1ccc(I)cc1)C(F)(F)C(F)(F)F</smiles><smiles>CC(C)(C)c1ccc(C(=O)C(F)(F)F)cc1</smiles>

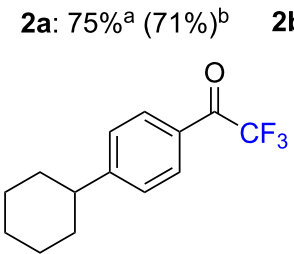

2b: $37 \%^{\mathrm{a}}(34 \%)^{\mathrm{b}}$

2c: $57 \%^{a}(52 \%)^{b}$

2d: $63 \%^{\mathrm{a}}(39 \%)^{\mathrm{b}}$

2e: $56 \%^{a}(51 \%)^{b}$

2f: $45 \%^{a}(38 \%)^{b}$<smiles>O=C(c1ccc(-c2ccccc2)cc1)C(F)(F)F</smiles><smiles>COc1ccc(C(=O)C(F)(F)F)cc1</smiles><smiles>O=C(c1cccc(Br)c1)C(F)(F)F</smiles><smiles>O=C(c1cccc(I)c1)C(F)(F)F</smiles><smiles>O=C(c1ccccc1Br)C(F)(F)F</smiles>

2g: $92 \%^{a}(77 \%)^{b}$

2h: $49 \%^{a}(38 \%)^{b}(43 \%)^{c} \quad$ 2i: $51 \%^{a}(45 \%)^{b}$

2j: $66 \%^{a}(60 \%)^{b}$

2k: $81 \%^{a}(75 \%)^{b}$

2I: $68 \%{ }^{a}(56 \%)^{b}$<smiles>O=C(c1ccccc1I)C(F)(F)F</smiles>

2m: $82 \%^{a}(77 \%)^{b}$<smiles>COc1ccc(C(=O)C(F)(F)F)cc1OC</smiles>

2n: $50 \%^{\mathrm{a}}(42 \%)^{\mathrm{b}}(40 \%)^{\mathrm{c}}$<smiles>O=C(C(F)(F)F)C12CC3CC(CC(C3)C1)C2</smiles>

2o: $62 \%^{\mathrm{a}}(58 \%)^{\mathrm{b}}$<smiles>O=C(/C=C/c1ccccc1)C(F)(F)F</smiles>

2p: $50 \%^{a}(41 \%)^{b}(36 \%)^{c}$

Scheme 3: Substrate scope of esters 1 for trifluoromethylation by $\mathrm{HCF}_{3}$ under the optimized conditions. ${ }^{\text {aDetermined by }}{ }^{19} \mathrm{~F}$ NMR of the crude 2 with trifluorotoluene as an internal standard. ' Isolated yield. Clsolated yield of gram-scale reaction by using $1 \mathrm{~g}$ of substrate.

carried out for $1 \mathbf{h}, \mathbf{1 n}$, and $1 \mathbf{p}$ to furnish $\mathbf{2 h}, \mathbf{2 p}$, and $\mathbf{2 n}$ in similar isolated yields, $43 \%, 40 \%$, and $36 \%$, respectively. The double $\mathrm{CF}_{3}$ addition product 3 was not observed due to the preferential formation of stable tetrahedral species $\mathbf{I}$ instead of the $\mathrm{CF}_{3}$ ketones 2 in the reaction mixture. However, all the yields were moderate to good. This fact could be explained by the appearance of hydrate products 4 in the ${ }^{19} \mathrm{~F}$ NMR spectrum of the crude reaction mixture [72], while the hydrates $\mathbf{4}$ disappeared completely after purification by silica gel column chromatography [73].

Given the relevance of this trifluoromethylation reaction system for drug discovery, we conducted a robustness screening experiment to gain further information on its tolerance to various pharmacophores (Table 2). A range of common nitrogen-containing compounds such as pyridine, pyrazine, $1 H$-pyrazole, $1 H$-indole, 1 -methyl- $1 H$-indole, piperidine, and piperazine were subjected to screening. Pyridine and piperidine slightly hamper the reaction of $\mathbf{1 g}$ (Table 2, entries 2 and 7, 80-82\%). Other nitrogen-containing compounds have more effect on the yield of the reaction of $\mathbf{1 g}$ (Table 2, entries 3-6, 58-72\%). Next, a range of common oxygen and sulfur-containing compounds such as furan, tetrahydrofuran, 1,4-dioxane, thiophene, benzo $[b]$ thiophene, dibenzo[b, $d]$ thiophene, and diphenylsulfane were also screened. These substances also have some effect on the reaction (Table 2, entries 9-15, 63-87\%). Besides, silicon-containing compound, trimethyl(phenyl)silane that is more sensitive to fluorine was screened, $79 \%$ yield were obtained in this test. To consider the frequency of these motifs in modern pharmaceutical drugs, these tests are necessary, and the resistance of the reaction was also verified from various pharmacophores to be acceptable.

\section{Conclusion}

In conclusion, the trifluoromethylation of methyl carboxylates to trifluoromethyl ketones is accomplished under basic conditions with fluoroform in triglyme at $-40{ }^{\circ} \mathrm{C}$. An equivalent amount of fluoroform was sufficient for this transformation. A wide variety of medicinally attractive aryl and alkyl trifluoromethyl ketones are obtained in good yields by a relatively simple procedure, although the protocol is not applicable to enolizable esters. Fluoroform is an economical feedstock, and 
Table 2: Tolerance of various pharmacophores under the trifluoromethylation conditions.

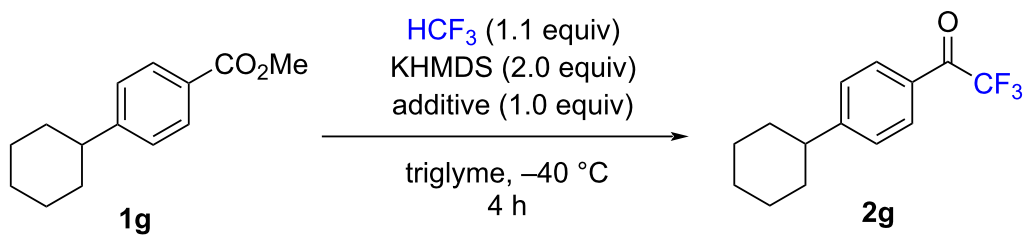

\begin{tabular}{|c|c|c|c|c|c|c|c|c|}
\hline Entry & Additive & Yield ${ }^{\mathrm{a}}(\%)$ & Entry & Additive & Yielda (\%) & Entry & Additive & Yield $^{\mathrm{a}}(\%)$ \\
\hline 1 & - & 92 & 7 & piperidine & 80 & 13 & benzo[ $[b]$ thiophene & 78 \\
\hline 2 & pyridine & 82 & 8 & piperazine & 64 & 14 & dibenzo $[b, d]$ thiophene & 64 \\
\hline 3 & pyrazine & 72 & 9 & furan & 87 & 15 & PhSPh & 75 \\
\hline 4 & pyrazole & 66 & 10 & THF & 64 & 16 & $\mathrm{Ph}_{-\mathrm{SiMe}_{3}}$ & 79 \\
\hline 5 & indole & 58 & 11 & 1,4-dioxane & 63 & & & \\
\hline 6 & 1-methyl-1H-indole & 67 & 12 & thiophene & 75 & & & \\
\hline
\end{tabular}

aDetermined by ${ }^{19} \mathrm{~F}$ NMR using the crude $\mathbf{2} \mathbf{g}$ with trifluorotoluene as an internal standard.

methyl esters are readily available inexpensive precursors. Besides, glymes are versatile solvents for chemical processes in industry [74] would the protocol be useful for the industrial extension, although there are still many points to be overcome such as requirements of low temperature, two equivalents of KHMDS. Further application of this "batch protocol" for a "continuous-flow microreactor" reaction is now ongoing in our laboratory towards industrial collaboration.

\section{Experimental}

A test tube containing $1(0.4 \mathrm{mmol})$ in triglyme $(0.7 \mathrm{~mL})$ was charged with $\mathrm{HCF}_{3}(9.9 \mathrm{~mL}, 1.1$ equiv, measured by a syringe, see the picture in Supporting Information File 1, Figure S1) by cooling in liquid nitrogen under vacuum. KHMDS (160 mg, 2.0 equiv) in triglyme (commercial grade, without drying, $0.3 \mathrm{~mL}$ ) was added at $-40{ }^{\circ} \mathrm{C}$ under nitrogen atmosphere, and the reaction mixture was stirred at the same temperature for $4 \mathrm{~h}$. Thereafter, $1 \mathrm{M} \mathrm{HCl}$ aq $(1.0 \mathrm{~mL})$ was added, and the aqueous layer was extracted with $\mathrm{CH}_{2} \mathrm{Cl}_{2}(1.0 \mathrm{~mL} \times 3)$. The combined organic layer was washed with brine, dried over $\mathrm{Na}_{2} \mathrm{SO}_{4}$, concentrated under reduced pressure, and purified by column chromatography on silica gel to give products 2 .

\section{Supporting Information}

\section{Supporting Information File 1}

Optimization of reaction conditions, general procedure and product characterization data.

[https://www.beilstein-journals.org/bjoc/content/ supplementary/1860-5397-17-39-S1.pdf]

\section{Funding}

This work was supported by JSPS KAKENHI grants JP 18 H02553 (KIBAN B, NS).

\section{ORCID ${ }^{\circledR}$ iDs}

Yumeng Liang - https://orcid.org/0000-0002-2846-0792 Norio Shibata - https://orcid.org/0000-0002-3742-4064

\section{References}

1. Zhu, Y.; Han, J.; Wang, J.; Shibata, N.; Sodeoka, M.; Soloshonok, V. A.; Coelho, J. A. S.; Toste, F. D. Chem. Rev. 2018, 118, 3887-3964. doi:10.1021/acs.chemrev.7b00778

2. Purser, S.; Moore, P. R.; Swallow, S.; Gouverneur, V. Chem. Soc. Rev. 2008, 37, 320-330. doi:10.1039/b610213c

3. Inoue, M.; Sumii, Y.; Shibata, N. ACS Omega 2020, 5, 10633-10640. doi:10.1021/acsomega.0c00830

4. Ogawa, Y.; Tokunaga, E.; Kobayashi, O.; Hirai, K.; Shibata, N. iScience 2020, 23, 101467. doi:10.1016/j.isci.2020.101467

5. Gillis, E. P.; Eastman, K. J.; Hill, M. D.; Donnelly, D. J.; Meanwell, N. A. J. Med. Chem. 2015, 58, 8315-8359. doi:10.1021/acs.jmedchem.5b00258

6. Park, B. K.; Kitteringham, N. R.; O'Neill, P. M. Annu. Rev. Pharmacol. Toxicol. 2001, 41, 443-470. doi:10.1146/annurev.pharmtox.41.1.443

7. Isanbor, C.; O'Hagan, D. J. Fluorine Chem. 2006, 127, 303-319. doi:10.1016/j.jluchem.2006.01.011

8. Wang, J.; Sánchez-Roselló, M.; Aceña, J. L.; del Pozo, C.; Sorochinsky, A. E.; Fustero, S.; Soloshonok, V. A.; Liu, H. Chem. Rev. 2014, 114, 2432-2506. doi:10.1021/cr4002879

9. Kirsch, P. Modern Fluoroorganic Chemistry Synthesis, Reactivity, Applications; Wiley-VCH: Weinheim, Germany, 2004. doi:10.1002/352760393x

10. Liang, T.; Neumann, C. N.; Ritter, T. Angew. Chem., Int. Ed. 2013, 52 , 8214-8264. doi:10.1002/anie.201206566 
11. Mazloomi, Z.; Bansode, A.; Benavente, P.; Lishchynskyi, A.; Urakawa, A.; Grushin, V. V. Org. Process Res. Dev. 2014, 18, 1020-1026. doi:10.1021/op500109v

12. Musio, B.; Gala, E.; Ley, S. V. ACS Sustainable Chem. Eng. 2018, 6, 1489-1495. doi:10.1021/acssuschemeng.7b04012

13. Harsanyi, A.; Sandford, G. Org. Process Res. Dev. 2014, 18, 981-992. doi:10.1021/op500141c

14. Caron, S. Org. Process Res. Dev. 2020, 24, 470-480. doi:10.1021/acs.oprd.0c00030

15. Glenadel, Q.; Alazet, S.; Baert, F.; Billard, T. Org. Process Res. Dev. 2016, 20, 960-964. doi:10.1021/acs.oprd.6b00062

16. McCulloch, A.; Lindley, A. A. Atmos. Environ. 2007, 41, 1560-1566. doi:10.1016/j.atmosenv.2006.02.021

17. Han, W.; Li, Y.; Tang, H.; Liu, H. J. Fluorine Chem. 2012, 140, 7-16. doi:10.1016/j.jluchem.2012.04.012

18. Grushin, V. V. Chim. Oggi 2014, 32 (3), 81-90.

19. Shono, T.; Ishifune, M.; Okada, T.; Kashimura, S. J. Org. Chem. 1991, 56, 2-4. doi:10.1021/jo00001a002

20. Symons, E. A.; Clermont, M. J. J. Am. Chem. Soc. 1981, 103, 3127-3130. doi:10.1021/ja00401a034

21. Barhdadi, R.; Troupel, M.; Périchon, J. Chem. Commun. 1998, 1251-1252. doi:10.1039/a801406j

22. Folléas, B.; Marek, I.; Normant, J.-F.; Jalmes, L. S. Tetrahedron Lett. 1998, 39, 2973-2976. doi:10.1016/s0040-4039(98)00391-8

23. Russell, J.; Roques, N. Tetrahedron 1998, 54, 13771-13782. doi:10.1016/s0040-4020(98)00846-1

24. Mispelaere, C.; Roques, N. Tetrahedron Lett. 1999, 40, 6411-6414. doi:10.1016/s0040-4039(99)01369-6

25. Folléas, B.; Marek, I.; Normant, J.-F.; Saint-Jalmes, L. Tetrahedron 2000, 56, 275-283. doi:10.1016/s0040-4020(99)00951-5

26. Large, S.; Roques, N.; Langlois, B. R. J. Org. Chem. 2000, 65, 8848-8856. doi:10.1021/j0000150s

27. Billard, T.; Bruns, S.; Langlois, B. R. Org. Lett. 2000, 2, 2101-2103. doi:10.1021/ol005987o

28. van der Born, D.; Herscheid, J. D. M.; Orru, R. V. A.; Vugts, D. J. Chem. Commun. 2013, 49, 4018-4020. doi:10.1039/c3cc37833k

29. Tomashenko, O. A.; Escudero-Adán, E. C.; Martínez Belmonte, M.; Grushin, V. V. Angew. Chem., Int. Ed. 2011, 50, 7655-7659. doi:10.1002/anie.201101577

30. Zanardi, A.; Novikov, M. A.; Martin, E.; Benet-Buchholz, J.; Grushin, V. V. J. Am. Chem. Soc. 2011, 133, 20901-20913. doi:10.1021/ja2081026

31. Lishchynskyi, A.; Novikov, M. A.; Martin, E.; Escudero-Adán, E. C.; Novák, P.; Grushin, V. V. J. Org. Chem. 2013, 78, 11126-11146. doi:10.1021/j0401423h

32. Lishchynskyi, A.; Berthon, G.; Grushin, V. V. Chem. Commun. 2014, 50, 10237-10240. doi:10.1039/c4cc04930f

33. Novák, P.; Lishchynskyi, A.; Grushin, V. V. J. Am. Chem. Soc. 2012, 134, 16167-16170. doi:10.1021/ja307783w

34. Novák, P.; Lishchynskyi, A.; Grushin, V. V. Angew. Chem., Int. Ed. 2012, 51, 7767-7770. doi:10.1002/anie.201201613

35. Konovalov, A. I.; Benet-Buchholz, J.; Martin, E.; Grushin, V. V. Angew. Chem., Int. Ed. 2013, 52, 11637-11641. doi:10.1002/anie.201306272

36. Konovalov, A. I.; Lishchynskyi, A.; Grushin, V. V. J. Am. Chem. Soc. 2014, 136, 13410-13425. doi:10.1021/ja507564p

37. Romine, A. M.; Nebra, N.; Konovalov, A. I.; Martin, E.; Benet-Buchholz, J.; Grushin, V. V. Angew. Chem., Int. Ed. 2015, 54, 2745-2749. doi:10.1002/anie.201411348
38. Prakash, G. K. S.; Jog, P. V.; Batamack, P. T. D.; Olah, G. A. Science 2012, 338, 1324-1327. doi:10.1126/science.1227859

39. He, L.; Tsui, G. C. Org. Lett. 2016, 18, 2800-2803. doi:10.1021/acs.orglett.6b00999

40. Xiang, J.-X.; Ouyang, Y.; Xu, X.-H.; Qing, F.-L. Angew. Chem., Int. Ed. 2019, 58, 10320-10324. doi:10.1002/anie.201905782

41. Geri, J. B.; Szymczak, N. K. J. Am. Chem. Soc. 2017, 139, 9811-9814. doi:10.1021/jacs.7b05408

42. Biggadike, K.; Boudjelal, M.; Clackers, M.; Coe, D. M.; Demaine, D. A.; Hardy, G. W.; Humphreys, D.; Inglis, G. G. A.; Johnston, M. J.; Jones, H. T.; House, D.; Loiseau, R.; Needham, D.; Skone, P. A.; Uings, I.; Veitch, G.; Weingarten, G. G.; McLay, I. M.; Macdonald, S. J. F. J. Med. Chem. 2007, 50, 6519-6534. doi:10.1021/jm070778w

43. Geri, J. B.; Wade Wolfe, M. M.; Szymczak, N. K. Angew. Chem., Int. Ed. 2018, 57, 1381-1385. doi:10.1002/anie.201711316

44. Han, Z.; Chen, S.; Tu, Y.; Lian, X.; Li, G. Eur. J. Org. Chem. 2019, 4658-4661. doi:10.1002/ejoc.201900250

45. Kawai, H.; Yuan, Z.; Tokunaga, E.; Shibata, N. Org. Biomol. Chem. 2013, 11, 1446-1450. doi:10.1039/c3ob27368g

46. Saito, T.; Wang, J.; Tokunaga, E.; Tsuzuki, S.; Shibata, N. Sci. Rep. 2018, 8, 11501. doi:10.1038/s41598-018-29748-1

47. Okusu, S.; Tokunaga, E.; Shibata, N. Org. Lett. 2015, 17, 3802-3805. doi:10.1021/acs.orglett.5b01778

48. Okusu, S.; Hirano, K.; Tokunaga, E.; Shibata, N. ChemistryOpen 2015, 4, 581-585. doi:10.1002/open.201500160

49. Punna, N.; Saito, T.; Kosobokov, M.; Tokunaga, E.; Sumii, Y.; Shibata, N. Chem. Commun. 2018, 54, 4294-4297. doi:10.1039/c8cc01526k

50. Hirano, K.; Saito, T.; Fujihira, Y.; Sedgwick, D. M.; Fustero, S.; Shibata, N. J. Org. Chem. 2020, 85, 7976-7985. doi:10.1021/acs.joc.0c00796

51. Lishchynskyi, A.; Miloserdov, F. M.; Martin, E.; Benet-Buchholz, J.; Escudero-Adán, E. C.; Konovalov, A. I.; Grushin, V. V. Angew. Chem., Int. Ed. 2015, 54, 15289-15293. doi:10.1002/anie.201507356

52. Miloserdov, F. M.; Konovalov, A. I.; Martin, E.; Benet-Buchholz, J.; Escudero-Adán, E. C.; Lishchynskyi, A.; Grushin, V. V. Helv. Chim. Acta 2017, 100, e1700032. doi:10.1002/hlca.201700032

53. Harlow, R. L.; Benet-Buchholz, J.; Miloserdov, F. M.; Konovalov, A. I.; Marshall, W. J.; Escudero-Adán, E. C.; Martin, E.; Lishchynskyi, A.; Grushin, V. V. Helv. Chim. Acta 2018, 101, e1800015. doi:10.1002/hlca.201800015

54. Prakash, G. K. S.; Wang, F.; Zhang, Z.; Haiges, R.; Rahm, M.; Christe, K. O.; Mathew, T.; Olah, G. A. Angew. Chem., Int. Ed. 2014, 53, 11575-11578. doi:10.1002/anie.201406505

55. Bégué, J.-P.; Bonnet-Delpon, D. Tetrahedron 1991, 47, 3207-3258. doi:10.1016/s0040-4020(01)86391-2

56. Kawase, M. J. Synth. Org. Chem., Jpn. 2001, 59, 755-765. doi:10.5059/yukigoseikyokaishi.59.755

57. Gelb, M. H.; Svaren, J. P.; Abeles, R. H. Biochemistry 1985, 24 , 1813-1817. doi:10.1021/bi00329a001

58. Frey, R. R.; Wada, C. K.; Garland, R. B.; Curtin, M. L.; Michaelides, M. R.; Li, J.; Pease, L. J.; Glaser, K. B.; Marcotte, P. A.; Bouska, J. J.; Murphy, S. S.; Davidsen, S. K. Bioorg. Med. Chem. Lett. 2002, 12, 3443-3447. doi:10.1016/s0960-894x(02)00754-0

59. Patricelli, M. P.; Patterson, J. E.; Boger, D. L.; Cravatt, B. F. Bioorg. Med. Chem. Lett. 1998, 8, 613-618. doi:10.1016/s0960-894x(98)00073-0 
60. Lehn, M.; Griessbach, K. Pharm. Pharmacol. Commun. 1999, 5, 389-393. doi:10.1111/j.1469-0691.1999.tb00846.x

61. Hornsperger, J.-M.; Collard, J.-N.; Heydt, J.-G.; Giacobini, E.; Funes, S.; Dow, J.; Schirlin, D. Biochem. Soc. Trans. 1994, 22 , 758-763. doi:10.1042/bst0220758

62. Parrilla, A.; Villuendas, I.; Guerrero, A. Bioorg. Med. Chem. 1994, 2, 243-252. doi:10.1016/s0968-0896(00)82167-7

63. Neises, B.; Broersma, R. J.; Tarnus, C.; Piriou, F.; Remy, J. M.; Lintz, C.; Heminger, E. F.; Kutcher, L. W. Bioorg. Med. Chem. 1995, 3, 1049-1061. doi:10.1016/0968-0896(95)00097-z

64. Patel, D. V.; Rielly-Gauvin, K.; Ryono, D. E.; Free, C. A.; Smith, S. A.; Petrillo, E. W., Jr. J. Med. Chem. 1993, 36, 2431-2447. doi:10.1021/jm00069a001

65. Kawase, M.; Harada, H.; Saito, S.; Cui, J.; Tani, S. Bioorg. Med. Chem. Lett. 1999, 9, 193-194. doi:10.1016/s0960-894x(98)00726-4

66. Wu, W.; Weng, Z. Synthesis 2018, 50, 1958-1964. doi:10.1055/s-0036-1591971

67. Kelly, C. B.; Mercadante, M. A.; Leadbeater, N. E. Chem. Commun. 2013, 49, 11133-11148. doi:10.1039/c3cc46266h

68. Wiedemann, J.; Heiner, T.; Mloston, G.; Prakash, G. K. S.; Olah, G. A. Angew. Chem., Int. Ed. 1998, 37, 820-821. doi:10.1002/(sici)1521-3773(19980403)37:6<820::aid-anie820>3.0.co; 2-m

69. Singh, R. P.; Cao, G.; Kirchmeier, R. L.; Shreeve, J. M. J. Org. Chem. 1999, 64, 2873-2876. doi:10.1021/jo982494c

70. Kawano, Y.; Kaneko, N.; Mukaiyama, T. Bull. Chem. Soc. Jpn. 2006, 79, 1133-1145. doi:10.1246/bcsj.79.1133

71. Cui, B.; Sun, H.; Xu, Y.; Duan, L.; Li, Y.-M. Tetrahedron 2017, 73 6754-6762. doi:10.1016/j.tet.2017.10.021

72. Kadoh, Y.; Tashiro, M.; Oisaki, K.; Kanai, M. Adv. Synth. Catal. 2015, 357, 2193-2198. doi:10.1002/adsc.201500131

73. Jiang, X.-D.; Matsukawa, S.; Kakuda, K.-i.; Fukuzaki, Y.; Zhao, W.-L.; Li, L.-S.; Shen, H.-B.; Kojima, S.; Yamamoto, Y. Dalton Trans. 2010, 39, 9823-9829. doi:10.1039/c0dt00539h

74. Tang, S.; Zhao, H. RSC Adv. 2014, 4, 11251-11287. doi:10.1039/c3ra47191h

\section{License and Terms}

This is an Open Access article under the terms of the Creative Commons Attribution License (https://creativecommons.org/licenses/by/4.0). Please note that the reuse, redistribution and reproduction in particular requires that the author(s) and source are credited and that individual graphics may be subject to special legal provisions.

The license is subject to the Beilstein Journal of Organic Chemistry terms and conditions: (https://www.beilstein-journals.org/bjoc/terms)

The definitive version of this article is the electronic one which can be found at: https://doi.org/10.3762/bjoc.17.39 